\title{
Prevalence of Bladder and Bowel Dysfunction in the Outpatient Clinic of Pediatric Urology and Nephrology
}

\section{Prevalencia de la disfunción de la vejiga y del intestino en la consulta ambulatoria de urología y nefrología pediátrica}

\author{
Catalina Barco-Castillo ${ }^{1,2}$ Natalia Mejía ${ }^{10}$ Mariana Echeverry ${ }^{1,2}$ Anamaría Ramos ${ }^{1}$ \\ Nicolás Fernández ${ }^{30}$ Jaime Pérez ${ }^{1}$
}

${ }^{1}$ Department of Urology, Pediatric Urology and Nephrology Clinic, Hospital
Universitario Fundación Santa Fe de Bogotá, Bogotá DC, Colombia
${ }^{2}$ School of Medicine, Universidad de los Andes, Bogotá DC, Colombia
${ }^{3}$ Division of Urology, Seattle Children's Hospital University of
Washington, Seattle, Washington, United States

Address for correspondence Jaime Pérez, MD, Cr 7118 09, Unidad Renal, tercer piso, Clínica de Urología, Bogotá, DC, Colombia (e-mail: drjaimeperez@urologiapediatricadecolombia.com).

Urol Colomb 2020;29:217-224.

\begin{abstract}
Keywords

- bladder and bowel dysfunction

- constipation

- lower-urinary-tract symptoms

- pediatric urology

- pediatric nephrology

- prevalence
\end{abstract}

\section{Resumen}

Objective Bladder and bowel dysfunction (BBD) is defined as the presence of functional alterations in both organs. The correct diagnosis and treatment prevent the exposure of patients to multiple antibiotic treatments, invasive procedures and radiological studies. The aim of the present study was to estimate the prevalence of BBD in the outpatient clinic of pediatric urology and nephrology.

Methods A prospective cohort composed of 334 patients aged between 5 and 18 years was evaluated. The Pediatric Lower Urinary Tract Symptom Score (PLUTSS) was applied. A score higher than 8 was considered as significant urinary symptomatology. Moreover, the Bristol Stool Scale and the Rome IV Criteria for functional constipation and fecal incontinence were used. Patients with organic pathologies were excluded. The risk factors were evaluated using logistic regression models.

Results The median age was 9 years old (interquartile range [IQR]: 6-13). The PLUTSS questionnaire was significant in $16.5 \%$ of the kids, constipation was found in $31.9 \%$, and fecal incontinence, in $4 \%$. The prevalence of BBD was of $27.8 \%$. The female gender (odds ratio [OR]: $2.47 ; p=0.002$ ) and psychological disorders (OR: $4.637 ; p=0.024$ ) were considered risk factors. The evaluation of the PLUTSS questionnaire showed relevance regarding incontinence (OR: 3.059; $p=0.038$ ), enuresis (OR: 8.532; $p<0.001$ ); intermittent flow (OR: 9.211; $p=0.004$ ), frequency (OR: 6.73; $p=0.005$ ), and constipation (OR: $34.46 ; p<0.001$ ).

Conclusions The prevalence of BBD is of $27.8 \%$ in the outpatient clinic. It is important to prevent associated complications and the exposure to multiple antibiotic treatments, as well as invasive and imaging procedures, which also generate high costs to the health system.

Objetivo El síndrome de disfunción de la vejiga y del intestino (DVI) se define como la presencia de alteraciones funcionales en ambos órganos. El correcto diagnóstico y received

April 10, 2020

accepted

May 26, 2020
DOI https://doi.org/

$10.1055 / \mathrm{s}-0040-1713925$

ISSN 0120-789X.

e ISSN 2027-0119.
Copyright ( 2020 , Sociedad Colombiana License terms de Urología. Publicado por Thieme Revinter Publicações Ltda., Rio de Janeiro, Brazil. Todos los derechos reservados.

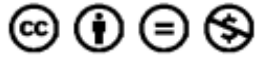




\section{Palabras clave}

- disfunción de la vejiga y del intestino

- estreñimiento

- síntomas del tracto urinario inferior

- urología pediátrica

- nefrología pediátrica

- prevalencia tratamiento previene la exposición de los pacientes a múltiples manejos antibióticos, procedimientos invasivos y estudios radiológicos. El objetivo de este estudio es estimar la prevalencia de DVI en la consulta ambulatoria de urología y nefrología pediátrica. Métodos Se evaluó una cohorte prospectiva de 334 pacientes de 5 a 18 años. Se aplicó el cuestionario de Puntuación de Síntomas del Tracto Urinario Inferior (Pediatric Lower Urinary Tract Symptom Score, PLUTSS), cuyo resultado mayor a 8 fue considerado significativo. Adicionalmente, se usó la Escala de Heces de Bristol (Bristol Stool Scale) y los Criterios Roma IV (Rome IV Criteria) para estreñimiento e incontinencia fecal. Los factores de riesgo se evaluaron bajo modelos de regresión logística.

Resultados La edad mediana fue de 9 años (rango intercuartil [RIC]: 6-13). El cuestionario PLUTSS fue significativo en $16,5 \%$ de los niños, y se observó estreñimiento en $31,9 \%$, e incontinencia fecal en $4 \%$. La prevalencia de DVI fue de $27,8 \%$. El sexo femenino (razón de probabilidades [RP]: $2.47 ; p=0.002$ ) y desordenes psicológicos (RP: $4.637 ; p=0.024)$ fueron considerados factores de riesgo. La evaluación del cuestionario PLUTSS mostró relevancia en incontinencia (RP: 3.059; $p=0.038$ ), enuresis (RP: 8.532; $p<0.001$ ), flujo intermitente (RP: 9.211; $p=0.004)$, frecuencia (RP: 6.73; $p=0.005)$, y estreñimiento (RP: 34.46; $p<0.001$ ).

Conclusiones La prevalencia de DVI fue de $27.8 \%$ en la consulta ambulatoria. Es importante prevenir complicaciones asociadas y la exposición a múltiples tratamientos antibióticos, procedimientos invasivos e imagenológicos, que adicionalmente generan altos costos al sistema de salud.

\section{Introduction}

The International Children's Continence Society (ICCS) defines bladder and bowel dysfunction (BBD) as the presence of functional alterations in these organs in children older than 5 years of age. ${ }^{1,2}$ It occurs due to the anatomical contiguity and the shared irrigation and innervation of the bladder and the bowel: dysfunction in one organ affects the function of the other., ${ }^{3,4}$ The symptoms include urinary incontinence, enuresis, nocturia and increased or decreased urinary frequency, constipation and encopresis. ${ }^{3,5}$

The presence of lower-urinary-tract symptoms (LUTSs) is a frequent reason for consultation in the pediatric urology and nephrology clinic, representing up to $40 \%$ of the cases. ${ }^{4}$ Worldwide, the prevalence of urinary incontinence is between $6.3 \%$ and $9 \%$ at the age of 7 years, decreasing to between $1.2 \%$ and $3 \%$ in teenagers. ${ }^{4}$ Likewise, constipation in the pediatric population has a prevalence of $\sim 0.3 \%$ to $8 \%{ }^{4}$ and of $\sim 4.2 \%$ to $32 \%$ when associated to voiding dysfunction. ${ }^{6-8}$ However, these data are variable and inconclusive. The complications include vesicoureteral reflux, urinary-tract infections (UTIs), abdominal pain, and emotional and behavioral disorders. ${ }^{4,5,9}$

The diagnosis of BBD is based on the clinical history focused on habits and voiding and bowel technique, as well as the documentation of the voiding diary and, in some cases, the measurement of the postvoid residual (PVR) volume, uroflowmetry with electromyography, and videourodynamic study. ${ }^{6,10,11}$ The physical examination should be aimed at ruling out pathologies such as obstruction of the lower urinary tract or neurological disorders. ${ }^{10,11}$ The treatment is based on the management of intestinal symptoms, improving the LUTSs. ${ }^{10,11}$
The aim of the present study is to estimate the prevalence of BBD in the outpatient clinic of pediatric urology and nephrology.

\section{Methods}

A prospective cohort composed of 334 patients aged between 5 and 18 years who attended the outpatient clinic of pediatric urology and nephrology was prospectively evaluated between April 4th, 2018 and April 3rd, 2019. The sample included all kids that attended the outpatient clinic during this period. The study protocol was approved by the Institutional Ethics Committee at Hospital Universitario Fundación Santa Fe de Bogotá, Bogotá, DC, Colombia, under the tenets of the Declaration of Helsinki. Before the consultation, an informed consent form was signed by the parents or legal guardians of the kids. Kids older than 7 years of age were asked for assessment.

All patients were evaluated for medical history, including gender, age, height and weight, history of prematurity, history of neurological, psychological, urological and nephrological disorders, history of UTI admission, and history of enuresis in the parents. A total of 86 patients with past history of myelomeningocele, spina bifida, refractory epilepsy, lysosomal storage diseases, Down syndrome, nephrectomy, urothelial carcinoma, hypospadias, vesicoureteral reflux and acute and chronic kidney injury were excluded.

During the consultation, the caregivers and the patients filled the version of the Pediatric Lower Urinary Tract Symptom Score (PLUTSS) translated into Spanish and validated by Somoza-Argibay et al, $^{12}$ and the Bristol Stool Scale to assess the patients with constipation. 
The PLUTSS questionnaire contains 15 questions that evaluate enuresis and incontinence, the subjective quantity of urine lost during the day and night, the LUTSs (storage and voiding), the habits to hold urination, the daily deposition, and the quality of life (QoL). A score higher than 8 was considered significant for LUTSs.

If needed, the patients were ruled out for UTIs with urinalysis and urine culture, and had their PVR volume evaluated by abdominal ultrasound, the uroflowmetry by electromyography, and a urodynamic study was also performed. The diagnosis of BBD was made after significant LUTSs measured by PLUTSS, history of UTI or PVR volume higher than $10 \%$ of the total bladder capacity, and constipation were observed.

The database was recorded using the Microsoft Excel for Mac (Microsoft Excel for MacOS, 2016, Microsoft Corp., Redmond, WA, US). The statistical analyses were performed using the Statistical Package for the Social Sciences (SPSS for MacOS, IBM Corp., Armonk, NY, US) software, version 25.0. The first analysis included all patients $(n=334)$ for evaluation of the medical history and exclusion criteria. The qualitative data were evaluated as frequencies, and the quantitative data were tested for normality using the Kolmogorov-Smirnoff test. If the data had normal distribution, they were reported as mean \pm standard deviation; otherwise, they were reported as median (interquartile range, IQR).

Out of de 334 patients surveyed, 86 did not meet the inclusion criteria. The remaining 248 patients were included in the second analysis. The data were described and then stratified by type of consultation (pediatric urology versus pediatric nephrology), and by diagnosis of BBD. All of the qualitative variables were compared using the Chi-squared test. The parametric quantitative data were compared using the Student $t$-test for independent samples, and the MannWhitney $U$ test for the non-parametric variables.

Univariate and multivariate analyses were performed to determine the risk factors for BBD. The variables included relevant medical history (gender, history of prematurity, neurological and psychological disorders, urinary tract malformation, hydronephrosis and enuresis in the parents) and every question of the PLUTSS questionnaire. In the analyses, $p$-values $<0.05$ were considered significant.

\section{Results}

The median age of the patients who attended the outpatient clinic was 9 years-old (IQR: 6-13), and median body surface area was $0.103 \mathrm{~m}^{2}$ (IQR: $0.085-0.143$ ). In total, the sample was composed of 174 (52.1\%) male patients and 160 (47.9\%) female patients. Regarding the medical history, prematurity was found in 174 (52.1\%) patients, neurologic disorders, in 28 (8.4\%), psychological disorders, in 13 (5.9\%), previous abdominal surgery, in 39 (11.7\%), intestinal disorders, in $3(0.9 \%)$, UTIs, in 103 (30.8\%), hydronephrosis, in 20 (6\%), anatomical malformation, in 22 (6.6\%), and kidney transplantation, in 7 (2.1\%) patients. A total of $86(25.7 \%)$ patients were excluded. The overall data can be found in - Table 1 .
Table 1 Characteristics of the patients who attended the clinic

\begin{tabular}{|c|c|}
\hline Variables & $n=334$ \\
\hline Age (years) f & $9(6-13)$ \\
\hline \multicolumn{2}{|l|}{ Gender $\Phi$} \\
\hline Female & $160(47.9)$ \\
\hline Male & $174(52.1)$ \\
\hline Body surface area $\left(\mathrm{m}^{2}\right) \neq$ & $0.103(0.085-0.143)$ \\
\hline Weeks of gestation at birth $\neq$ & $39(36-40)$ \\
\hline History of prematurity $\Phi$ & $62(29.5)$ \\
\hline \multicolumn{2}{|l|}{ Neurological disorders $\Phi$} \\
\hline Myelomeningocele & $7(2.1)$ \\
\hline Hypotonia & $1(0.3)$ \\
\hline Down syndrome & $1(0.3)$ \\
\hline Arteriovenous malformation & $1(0.3)$ \\
\hline Spina bifida & $2(0.6)$ \\
\hline Epilepsy & $10(3)$ \\
\hline Neurofibromatosis & $3(0.9)$ \\
\hline Brain tumor & $1(0.3)$ \\
\hline Lysosomal storage disease & $1(0.3)$ \\
\hline Asperger syndrome & $1(0.3)$ \\
\hline \multicolumn{2}{|l|}{ Psychological disorders $\Phi$} \\
\hline $\begin{array}{l}\text { Attention deficit } \\
\text { hyperactivity disorder }\end{array}$ & $6(1.8)$ \\
\hline Traumatic event in the past & $3(0.9)$ \\
\hline $\begin{array}{l}\text { Anxiety and obsessive- } \\
\text { compulsive disorder }\end{array}$ & $2(0.6)$ \\
\hline History of urinary-tract infection $\Phi$ & $103(30.8)$ \\
\hline One episode & $46(14.7)$ \\
\hline Two or more episodes & $34(10.7)$ \\
\hline History of hydronephrosis $\Phi$ & $20(6)$ \\
\hline History of urinary malformation $\Phi$ & $22(6.6)$ \\
\hline History of vesicoureteral reflux $\Phi$ & $34(10.2)$ \\
\hline \multicolumn{2}{|l|}{ Enuresis in the parents $\Phi$} \\
\hline Father & $1(0.3)$ \\
\hline Mother & $2(0.6)$ \\
\hline Excluded patients $\Phi$ & $86(25.7)$ \\
\hline
\end{tabular}

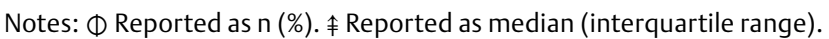

When compared by type of consultation (pediatric urology versus pediatric nephrology), there were more males in the urology group $(90.6 \%$ versus $44 \%$;. $p<0.001)$. The week of gestation at birth was higher for the nephrology group (36.5 [IQR: $35-39]$ versus 40 [IQR: $36-40]$; $p=0.005$ ); however, there were no differences regarding the history of prematurity. Moreover, the history of psychological disorders (12.5 versus $0 \% ; p<0.001$ ), abdominal surgery (17.2 versus $3.3 ; p=0.001$ ) and enuresis in the kid's parents ( 3.1 versus $0.5 \% ; p=0.047$ ) were higher in the urology group, while the history of UTIs was lower (14.1 versus $32.6 \%$; $p=0.004$ ). 
During the consultation, more patients in the nephrology group needed abdominal ultrasound (18.8 versus $44.6 \%$; $p<0.001$ ); however, less patients had a significant PVR volume (18.8 versus $6.5 \% ; p=0.004)$. As for the PLUTSS questionnaire, the diagnosis of constipation or fecal incontinence, and the diagnosis of BBD, there were no differences between the groups. The overall prevalence of BBD was of $27.8 \%$. The prevalence in the pediatric urology clinic was of $26.6 \%$, and in the pediatric nephrology clinic it was of $28.3 \%$. All data stratified by type of consultation are in - Table 2 .

The children with diagnosis of BBD were younger $(7$ years [IQR: $5-8$ ] versus 11 years [IQR: $7-14$ ]; $p<0.001)$. Additionally, BBD was more frequent in females (37.6 versus $20.1 \%$; $p=0.002)(-$ Table 3$)$. There were no differences between the groups regarding past medical history.

In the univariate analysis, we found that being female (odds ratio [OR]: 2.47 [95\% confidence interval (95\%CI: 1.389-4.4)]; $p=0.002$ ) and having psychological disorders (OR: 4.637 [95\% CI: $1.224-17.558] ; p=0.024)$ like trauma, obsessive-compulsive disorder $(\mathrm{OCD})$, anxiety and attention deficit hyperactivity disorder (ADHD) were a risk factors for BBD.

Moreover, the analysis of the questionnaire showed as risk factors incontinence (question 2; OR: 3.059 [95\%CI: 1.067-8.776]; $p=0.038$ ), enuresis (question 3; OR: 8.532 [95\%CI: 2.7-26.96]; $p<0.001$ ), intermittent flow (question 8; OR: 9.211 [2.011-42.196]; $p=0.004$ ), frequency (question 9; OR: 6.73 [95\%CI: $1.788-25.33$ ]; $p=0.005$ ) and constipation (question 13; OR: 34.46 [95\%CI: 13.393-88.666]; $p<0.001)$. The summary of the regression analysis of the risk factors for BBD is in $=$ Table 4.

\section{Discussion}

The true incidence of BBD is unknown, ${ }^{13}$ and the prevalence is inconclusive due to the lack of studies on the subject. Burgers et $\mathrm{al}^{14}$ studied BBD in a cohort of 113 patients who attended the pediatric urology clinic due to LUTSs, and they found a prevalence of $47 \%$. Vaz et al, ${ }^{15}$ in a population of 739 schoolchildren, found a prevalence of symptoms of lowerurinary-tract dysfunction in $21.8 \%$ of the cases, and of constipation in $30.7 \%$. In the present study, the prevalence of BBD in the pediatric urology consultation was of $26.6 \%$; in the pediatric nephrology consultation, it was of $28.3 \%$; and the overall prevalence was of $27.8 \%$. These differences can be attributed to the different inclusion criteria of each study. We included all patients who attended the clinic, and only excluded kids with pathologies that could explain the LUTSs, the history of UTI, or the constipation.

In the present study, there were more male patients; however, the prevalence of BBD was higher in the female population (41 $(59.4 \%)$ cases versus $28(40.6 \%)$ cases; $p=0.002$ ). Moreover, being of the female gender increased the risk of developing BBD, with a ratio of 2.5:1 in relation to the male gender. In the study by Vaz et $\mathrm{al},{ }^{15}$ the authors found an association of lower-urinary-tract dysfunction and the female gender, with an OR: of 3.7 (95\%CI: $2.5-5.7 ; p<0.001$ ). It is hypothesized that in women there are inappropriate activities of the pelvic floor muscles and/or the urethral sphincter during voiding, causing functional bladder outlet obstruction (BOO). ${ }^{16}$

The relevant medical history showed no differences between the populations with or without BBD; however, when the categories were stratified by the presence or not of the corresponding disorder, the psychological history increased the chance of developing BBD, with a ratio of 4.6:1 patient. The psychological diagnosis included trauma, OCD, anxiety and ADHD. Yang et al ${ }^{17}$ evaluated 130 patients in the pediatric urology clinic and stratified the results by ADHD diagnosis. They stated that kids with ADHD presented more soaked underwear and urgency. ${ }^{17}$ Additionally, Arlen et al ${ }^{18}$ presented 25 patients with phantom urinary incontinence and concomitant LUTSs and constipation, and 70\% of the kids had a diagnosis of OCD. And in a comparison of 38 kids with LUTSs versus 38 kids without LUTSs, Zhao et al ${ }^{19}$ found an anxiety level score higher in the group with LUTSs (3.68 versus 0.97 ; $p<0.001$ ).

On the other hand, the PLUTSS questionnaire showed a significant association between LUTSs and BBD when the score was higher than 8 points. ${ }^{12}$ When evaluating the association of each question with the diagnosis of BBD, the risk was 3.06 times higher for incontinence, 8.53 times higher for enuresis, 9.21 times higher for intermittent flow, 6.73 times higher for frequency, and 34.46 times higher for constipation. We believe that reducing the PLUTSS questionnaire to only these five questions would speed up the consultation without resulting in the underdiagnosis of the patients with LUTSs.

Once the patient is diagnosed with BBD and other diagnosis are ruled out, it is important to focus the treatment in the urinary and bowel symptomatology at the same time. The constipation should be assessed and managed with a high amount of fluids and increased ingestion of dietary fiber, as well as stool softeners ${ }^{20}$ concomitant with behavioral recommendations for micturition. Polyethylene glycol (PEG) is the most commonly used stool softener, and it should be administer to all patients with LUTSs. ${ }^{20}$ In cases of recurrent UTIs, the antibacterial prophylaxis can be prescribed, ${ }^{21,22}$ specifically for the patients with vesicoureteral reflux and changes in the renal cortex. ${ }^{23}$ The misconception regarding antibiotic prophylaxis might increase bacterial resistance. Toska and Geitona ${ }^{24}$ evaluated 301 doctors and nurses about the prescription of antibiotics in the pediatric population, and found irrational prescribing in $56 \%$ of the cases due to uncertainty regarding the diagnosis. Thus, the right diagnosis and evaluation, as well as the management with dietary and behavioral changes, are important to avoid the prescription of prophylactic or therapeutic antibiotics due to the complications of an undermanaged BBD.

Pediatric patients are up to 10 times more sensible to radiation than adults. ${ }^{25}$ This vulnerability leads physicians to try to reduce the number of imaging procedures performed on them. In case the patient with BBD is resistant to therapy or a functional or anatomical dysfunction is suspected, the images must be taken according to the as low as reasonably achievable (ALARA) protocol. ${ }^{25,26}$ In our cohort, $50 \%$ of the patients needed imaging evaluations, and they were first submitted to ultrasonography. Only $9.7 \%$ of the kids presented 
Table 2 Evaluation of the included patients stratified by type of consultation

\begin{tabular}{|c|c|c|c|}
\hline & Pediatric urology & Pediatric nephrology & \multirow[t]{2}{*}{ p-value } \\
\hline Variables & $n=64$ & $n=184$ & \\
\hline \multicolumn{4}{|l|}{ Relevant medical history } \\
\hline Age (years) $\neq$ & $9(6-14)$ & $9(6.75-13)$ & 0.988 \\
\hline Gender $\Phi$ & & & $<0.001$ \\
\hline Female & $6(9.4)$ & $103(56)$ & \\
\hline Male & $58(90.6)$ & $81(44)$ & \\
\hline Body surface area $\left(\mathrm{m}^{2}\right) \neq$ & $0.107(0.083-0.149)$ & $0.102(0.086-0.142)$ & 0.803 \\
\hline Weeks of gestation at birth $\neq$ & $36.5(35-39)$ & $40(36-40)$ & 0.005 \\
\hline History of prematurity $\Phi$ & $16(37.2)$ & $32(26.4)$ & 0.183 \\
\hline Neurological disorders $\Phi$ & $6(9.4)$ & $7(3.8)$ & 0.192 \\
\hline Psychological disorders $\Phi$ & $8(12.5)$ & $0(0)$ & $<0.001$ \\
\hline History of UTI $\Phi$ & $9(14.1)$ & $60(32.6)$ & 0.004 \\
\hline One episode & $4(6.3)$ & $30(17.5)$ & \multirow[t]{2}{*}{0.245} \\
\hline Two or more episodes & $5(7.8)$ & $17(9.3)$ & \\
\hline History of hydronephrosis $\Phi$ & $5(7.8)$ & $11(6)$ & 0.288 \\
\hline History of urinary malformation $\Phi$ & $0(0)$ & $15(8.2)$ & 0.593 \\
\hline Enuresis in the parents $\Phi$ & $2(3.1)$ & $1(0.5)$ & 0.047 \\
\hline \multicolumn{4}{|l|}{ Evaluation of $B B D$} \\
\hline PLUTSS score 手 & $1(0-5.75)$ & $0(0-4.75)$ & 0.234 \\
\hline Incontinence $\Phi$ & $12(18.7)$ & $32(17.4)$ & 0.875 \\
\hline Enuresis $\Phi$ & $11(17.2)$ & $23(12.5)$ & 0.695 \\
\hline Frequency $\Phi$ & 7 (11.9) & $21(11.4)$ & 0.700 \\
\hline Voiding symptoms $\Phi$ & $20(7.8)$ & $40(5.43)$ & 0.128 \\
\hline Urgency $\Phi$ & $12(9.38)$ & 39 (10.59) & 0.640 \\
\hline Hold urination $\Phi$ & $14(21.9)$ & 35 (19) & 0.621 \\
\hline Daily deposition $\Phi$ & $47(73.4)$ & $141(76.6)$ & 0.607 \\
\hline Affected quality of life $\Phi$ & $6(9.4)$ & $15(8.1)$ & 0.437 \\
\hline Diagnosis of significant LUTS $\Phi$ & $10(15.6)$ & $31(16.8)$ & 0.821 \\
\hline Bristol Stool Scale $\Phi$ & & & 0.014 \\
\hline 1 & $1(2.1)$ & $22(19.3)$ & \\
\hline 2 & $7(14.6)$ & $24(21.1)$ & \\
\hline 3 & $15(31.3)$ & $25(21.9)$ & \\
\hline 4 & $25(52.1)$ & $43(37.7)$ & \\
\hline Diagnosis of constipation $\Phi$ & $18(28.1)$ & $61(33.2)$ & 0.457 \\
\hline Encopresis $\Phi$ & $2(3.1)$ & $8(4.3)$ & 0.668 \\
\hline \multicolumn{4}{|c|}{ Additional laboratories or imaging studies } \\
\hline Infectious urinalysis $\Phi$ & $2(11.8)$ & $12(9.3)$ & 0.746 \\
\hline Positive urine culture $\Phi$ & $3(33.3)$ & $12(27.9)$ & 0.134 \\
\hline PVR volume $(\mathrm{mL})$ f & $9.5(2-14.75)$ & $8.5(0.975-8.5)$ & 0.920 \\
\hline Significant PVR $\Phi$ & $12(18.8)$ & $12(6.5)$ & 0.004 \\
\hline \multicolumn{4}{|l|}{ Diagnosis of BBD } \\
\hline Global prevalence $\Phi$ & \multicolumn{3}{|l|}{$69(27.8)$} \\
\hline Stratified prevalence $\Phi$ & $17(26.6)$ & $52(28.3)$ & 0.794 \\
\hline
\end{tabular}

Abbreviations: BBD, bladder and bowel dysfunction; LUTS, lower-urinary-tract symptoms; PLUTSS, Pediatric Lower Urinary Tract Symptom Score; PVR, postvoid residual; UTI, urinary-tract infection.

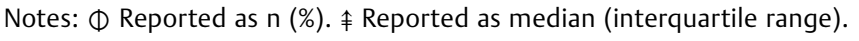


Table 3 Characteristics of the patients stratified by diagnosis of bladder and bowel dysfunction

\begin{tabular}{|l|l|l|l|}
\hline Variables & Patient with bladder and bowel dysfunction & Healthy patient & p-value \\
\hline & $n=69$ & $n=179$ & \\
\hline Age (years) f & $11(7-14)$ & $7(5-8)$ & $<0.001$ \\
\hline Gender $\Phi$ & & & 0.002 \\
\hline Female & $41(59.4)$ & $68(38)$ & \\
\hline Male & $28(40.6)$ & $111(62)$ & \\
\hline Body surface area $\left(m^{2}\right.$ f & $0.120(0.089-0.153)$ & $0.092(0.075-0.102)$ & $<0.001$ \\
\hline Weeks of gestation at birth f & $39.5(36-40)$ & $38(35.75-40)$ & 0.182 \\
\hline History of prematurity $\Phi$ & $16(34.8)$ & $32(27.1)$ & 0.333 \\
\hline Neurological disorders $\Phi$ & $4(5.8)$ & $9(5)$ & 0.636 \\
\hline Psychological disorders $\Phi$ & $6(8.7)$ & $4(2.2)$ & 0.100 \\
\hline History of hydronephrosis $\Phi$ & $4(5.8)$ & $12(6.7)$ & 0.746 \\
\hline History of urinary malformation $\Phi$ & $13(7.3)$ & $2(2.9)$ & $2(1.2)$ \\
\hline Enuresis in parents $\Phi$ & $1(1.4)$ & & 0.939 \\
\hline
\end{tabular}

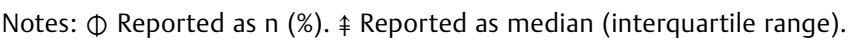

Table 4 Regression analysis of the various risk factors for bladder and bowel dysfunction

\begin{tabular}{|c|c|c|c|c|}
\hline Variables & Univariate analysis* & & Multivariate analysis** & \\
\hline & OR $(95 \% \mathrm{Cl}$ & p-value & Adjusted OR (95\%CI) & p-value \\
\hline \multicolumn{5}{|l|}{ Baseline characteristics } \\
\hline Gender (female) & $2.39(1.355-4.216)$ & 0.002 & $2.472(1.389-4.4)$ & 0.002 \\
\hline History of prematurity & $1.433(0.691-2.974)$ & 0.333 & 1 & $\mathrm{~N} / \mathrm{A}$ \\
\hline Neurological disorders & $1.162(0.349-3.906)$ & 0.808 & 1 & $\mathrm{~N} / \mathrm{A}$ \\
\hline Psychological disorders & $4.167(1.138-15.251)$ & 0.020 & $4.637(1.224-17.558)$ & 0.024 \\
\hline History of hydronephrosis & $0.856(0.267-2.752)$ & 0.794 & 1 & $\mathrm{~N} / \mathrm{A}$ \\
\hline History of urinary malformation & $0.381(0.084-1.735)$ & 0.196 & 1 & $\mathrm{~N} / \mathrm{A}$ \\
\hline Enuresis in the parents & $1.301(0.116-14.588)$ & 0.830 & 1 & $\mathrm{~N} / \mathrm{A}$ \\
\hline \multicolumn{5}{|l|}{ Questionnaire } \\
\hline Incontinence & $9.066(4.395-18.701)$ & $<0.001$ & 1 & $\mathrm{~N} / \mathrm{A}$ \\
\hline Quantitative incontinence & $10.09(4.737-21.489)$ & $<0.001$ & $3.059(1.067-8.776)$ & 0.038 \\
\hline Enuresis & $5.587(2.606-11.977)$ & $<0.001$ & $8.532(2.7-26.96)$ & $<0.001$ \\
\hline Quantitative enuresis & $5.587(2.606-11.977)$ & $<0.001$ & 1 & $\mathrm{~N} / \mathrm{A}$ \\
\hline Polaquiuria & $3(1.346-6.685)$ & 0.005 & 1 & $\mathrm{~N} / \mathrm{A}$ \\
\hline Straining & $4.94(1.398-17.452)$ & 0.007 & 1 & $\mathrm{~N} / \mathrm{A}$ \\
\hline Voiding pain & $3.418(0.89-13.127)$ & 0.059 & 1 & $\mathrm{~N} / \mathrm{A}$ \\
\hline Intermittent flow & $6.6(2.201-19.79)$ & $<0.001$ & $9.211(2.011-42.196)$ & 0.004 \\
\hline Frequency & $10.176(3.837-26.987)$ & $<0.001$ & $6.73(1.788-25.33)$ & 0.005 \\
\hline Urgency & $7.178(3.057-16.852)$ & $<0.001$ & 1 & $\mathrm{~N} / \mathrm{A}$ \\
\hline Holding & $6.478(3.305-12.695)$ & $<0.001$ & 1 & $\mathrm{~N} / \mathrm{A}$ \\
\hline Wetting & $5.938(2.388-14.765)$ & $<0.001$ & 1 & $\mathrm{~N} / \mathrm{A}$ \\
\hline Constipation & $20.5(9.933-42.307)$ & $<0.001$ & $34.46(13.393-88.666)$ & $<0.001$ \\
\hline
\end{tabular}

Abbreviations:95\% Cl, 95\% confidence interval; N/A, not available; OR, odds ratio.

Notes: ${ }^{*}$ Chi-squared test. ${ }^{* *}$ Logistic regression. 
positive findings for high PVR volume, but we did not find patients with urological malformations.

The Center for Child Incontinence at the Aarhus University Hospital, in Denmark, has a multidisciplinary team (pediatric nephrology, urology, urotherapy, psychology, sleep disorders, genetics and constipation) that treats children with nocturnal enuresis, overactive bladder and BBD. ${ }^{27}$ In a study ${ }^{27}$ with 400 patients, they concluded that most of them could be treated in primary care, and that the specialized clinics should assess therapy-resistant patients and kids with underlying pathologies. The creation of an specialized clinic on BBD in our hospital would help us improve and speed up the diagnosis of BBD and the beginning of the non-antibacterial non-pharmacological management of the patients. Moreover, a multidisciplinary team involving pediatric gastroenterology, urotherapy and nursing under a protocol of recurrent UTIs or therapy-resistant BBD management might prioritize patients, reducing complications and the rate of admissions to the inpatient care facility, as well as the need for imaging or invasive procedures and antibacterial therapy, thus reducing the costs to the healthcare system.

The limitations of the present study include the missing data regarding the PVR volume, the urinalysis and the urine culture in some patients. However, we believe that assessing the prevalence in the pediatric urology and nephrology clinic would help physicians to prevent complications, hospitalizations, the management with antibiotics and invasive or imaging procedures.

\section{Conclusion}

The prevalence of BBD is of $27.8 \%$ in our outpatient clinic. Adequate evaluation, diagnosis and management are important to prevent the associated complications and the exposure to multiple antibiotic treatments and invasive and imaging procedures. With the creation of a standardized transdisciplinary BBD clinic, physicians would assess the patients easily and better, thus decreasing the costs to the healthcare system.

\section{Funding sources}

The present study was supported by a research grant from the Joint Call for Research of Hospital Universitario Fundación Santa Fe de Bogotá and the School of Medicine at Universidad de los Andes (August 17 ${ }^{\text {th }}, 2018$ ).

\section{Conflict of interests}

The authors have no conflict of interests to declare.

\section{Acknowledgments}

We would like to thank the Joint Call for Research of Hospital Universitario Fundación Santa Fe de Bogotá and the School of Medicine at Universidad de los Andes School of Medicine for the research grant.

\section{References}

1 Franco I, Austin PF, Bauer SB, von Gontard A, Homsy Y, eds. Pediatric incontinence: Evaluation and clinical management [Internet]. Chi- chester, UK: John Wiley \& Sons, Ltd; 2015 [cited 2018 Jun 6]. Available from: http://doi.wiley.com/10.1002/9781118814789

2 Austin PF, Bauer SB, Bower W, et al. The standardization of terminology of lower urinary tract function in children and adolescents: Update report from the standardization committee of the International Children's Continence Society. Neurourol Urodyn 2016;35(04):471-481

3 Borch L, Hagstroem S, Bower WF, Siggaard Rittig C, Rittig S. Bladder and bowel dysfunction and the resolution of urinary incontinence with successful management of bowel symptoms in children. Acta Paediatr 2013;102(05):e215-e220

4 Sampaio C, Sousa AS, Fraga LGA, Veiga ML, Bastos Netto JM, Barroso U Jr. Constipation and Lower Urinary Tract Dysfunction in Children and Adolescents: A Population-Based Study. Front Pediatr 2016; 4:101http://journal.frontiersin.org/article/10.3389/fped.2016.00101

5 van Engelenburg-van Lonkhuyzen ML, Bols EMJ, Bastiaenen CHG, Benninga MA, de Bie RA. Childhood Bladder and Bowel Dysfunction Questionnaire: Development, Feasibility and Aspects of Validity and Reliability. J Pediatr Gastroenterol Nutr 2017;64(06):911-917

6 Chase J, Austin P, Hoebeke P, McKenna P; International Children's Continence Society. The management of dysfunctional voiding in children: a report from the Standardisation Committee of the International Children's Continence Society. J Urol 2010;183(04): 1296-1302

7 Hoebeke P, Van Laecke E, Van Camp C, Raes A, Van De Walle J. One thousand video-urodynamic studies in children with non-neurogenic bladder sphincter dysfunction. BJU Int 2001;87(06):575-580

8 von Gontard A. Enuresis im Kindesalter: Psychiatrische, somatische and molekulargenetische Zummenhänge. Professorial thesis (Habilitation): University of Cologne; 1995

9 Koff SA, Murtagh DS. The uninhibited bladder in children: effect of treatment on recurrence of urinary infection and on vesicoureteral reflux resolution. J Urol 1983;130(06):1138-1141

10 Schulman SL. Voiding dysfunction in children. Urol Clin North Am 2004;31(03):481-490, ix

11 KoffSA, Wagner TT, Jayanthi VR. The relationship among dysfunctional elimination syndromes, primary vesicoureteral reflux and urinary tract infections in children. J Urol 1998;160(3 Pt 2):1019-1022

12 Somoza-Argibay I, Méndez-Gallart R, Rodríguez-Ruíz M, Vergara I, Pértega $S$, Akbal C. [Validation of the spanish version of the pediatric lower urinary tract symptoms scale (PLUTSS)]. Arch Esp Urol 2017;70(07):645-653

13 Aguiar LM, Franco I. Bladder Bowel Dysfunction. Urol Clin North Am 2018;45(04):633-640

14 Burgers R, de Jong TPVM, Visser M, Di Lorenzo C, Dijkgraaf MGW, Benninga MA. Functional defecation disorders in children with lower urinary tract symptoms. J Urol 2013;189(05):1886-1891

15 Vaz GT, Vasconcelos MM, Oliveira EA, et al. Prevalence of lower urinary tract symptoms in school-age children. Pediatr Nephrol 2012;27(04):597-603

16 Peng C-H, Chen S-F, Kuo H-C. Videourodynamic analysis of the urethral sphincter overactivity and the poor relaxing pelvic floor muscles in women with voiding dysfunction. Neurourol Urodyn 2017;36(08):2169-2175

17 Yang S, Chua ME, Bauer S, et al. Diagnosis and management of bladder bowel dysfunction in children with urinary tract infections: a position statement from the International Children's Continence Society. Pediatr Nephrol 2018;33(12):2207-2219. Doi: $10.1007 / \mathrm{s} 00467-017-3799-9$

18 Arlen AM, Dewhurst LL, Kirsch SS, Dingle AD, Scherz HC, Kirsch AJ. Phantom urinary incontinence in children with bladder-bowel dysfunction. Urology 2014;84(03):685-688

19 Zhao PT, Velez D, Faiena I, Creenan EM, Barone JG. Bullying has a potential role in pediatric lower urinary tract symptoms. J Urol 2015;193(5, Suppl)1743-1748

20 Santos JD, Lopes RI, Koyle MA. Bladder and bowel dysfunction in children: An update on the diagnosis and treatment of a common, 
224 Prevalence of Bladder and Bowel Dysfunction Barco-Castillo et al.

but underdiagnosed pediatric problem. Can Urol Assoc J 2017;11 (1-2Suppl1):S64-S72

21 Shaikh N, Hoberman A, Keren R, et al. Recurrent Urinary Tract Infections in Children With Bladder and Bowel Dysfunction. Pediatrics 2016;137(01):e20152982

22 Robinson JL, Le Saux N. Management of urinary tract infections in children in an era of increasing antimicrobial resistance. Expert Rev Anti Infect Ther 2016;14(09):809-816

23 Peters CA, Skoog SJ, Arant BS Jr, et al. Summary of the AUA Guideline on Management of Primary Vesicoureteral Reflux in Children. J Urol 2010;184(03):1134-1144

24 Toska A, Geitona M. Antibiotic resistance and irrational prescribing in paediatric clinics in Greece. Br J Nurs 2015;24(01):28-33
25 Strauss KJ, Kaste SC. The ALARA (as low as reasonably achievable) concept in pediatric interventional and fluoroscopic imaging: striving to keep radiation doses as low as possible during fluoroscopy of pediatric patients-a white paper executive summary. Radiology 2006;240(03):621-622

26 Munro L. Basic of radiation protection. How to achieve ALARA: Working tips and guidelines. World Health Organization; 2004

27 Rittig S. Childhood incontinence highlights from the Aarhus Ghent Spring School (and ICCS) - PDF [Internet]. [cited 2019 Aug 2]. Available from: https://docplayer.net/12002577-Childhood-incontinence-highlights-from-the-aarhus-ghent-springschool-and-iccs.html 